\title{
ERK3 associates with MAP2 and is involved in glucose-induced insulin secretion
}

\author{
Gabriel F. Anhể ${ }^{a}$, Andréa S. Torrão ${ }^{a}$, Tatiane C.A. Nogueira ${ }^{a}$, Luciana C. Caperuto ${ }^{a}$, \\ Maria E.C. Amaral ${ }^{b}$, Mayrin C. Medina ${ }^{a}$, Anna K. Azevedo-Martins ${ }^{\mathrm{a}}$, \\ Angelo R. Carpinelli ${ }^{\text {a }}$, Carla R.O. Carvalho ${ }^{\text {a }}$, Rui Curi ${ }^{\text {a }}$, \\ Antonio C. Boschero ${ }^{b}$, Silvana Bordin ${ }^{a}$,* \\ ${ }^{a}$ Department of Physiology and Biophysics, Institute of Biomedical Sciences, University of São Paulo (USP), 05508-900 São Paulo, Brazil \\ ${ }^{\mathrm{b}}$ Department of Physiology and Biophysics, Institute of Biology, State University of Campinas (UNICAMP), 13083-970 Campinas, SP, Brazil
}

Received 4 January 2006; accepted 14 February 2006

\begin{abstract}
Summary
The adaptation of pancreatic islets to pregnancy includes increased $\beta$ cell proliferation, expansion of islet mass, and increased insulin synthesis and secretion. Most of these adaptations are induced by prolactin (PRL). We have previously described that in vitro PRL treatment increases ERK3 expression in isolated rat pancreatic islets. This study shows that ERK3 is also upregulated during pregnancy. Islets from pregnant rats treated with antisense oligonucleotide targeted to the PRL receptor displayed a significant reduction in ERK3 expression. Immunohistochemical double-staining showed that ERK3 expression is restricted to pancreatic $\beta$ cells. Transfection with antisense oligonucleotide targeted to ERK3 abolished the insulin secretion stimulated by glucose in rat islets and by PMA in RINm5F cells. Therefore, we examined the participation of ERK3 in the activation of a cellular target involved in secretory events, the microtubule associated protein MAP2. PMA induced ERK3 phosphorylation that was companied by an increase in ERK3/MAP2 association and MAP2 phosphorylation. These observations provide evidence that ERK3 is involved in the regulation of stimulus-secretion coupling in pancreatic $\beta$ cells.
\end{abstract}

(C) 2006 Elsevier Ireland Ltd. All rights reserved.

Keywords: Pancreatic islets; Insulin secretion; ERK3; MAP2

\section{Introduction}

The family of serine/threonine kinases known as extracellular signal-regulated kinases (ERKs) is composed by a large number of ubiquitous proteins being activated by a variety of hormones and growth factors (Pearson et al., 2001). In general, cell stimulation induces a signaling cascade that leads to phosphorylation of MEK (MAPK/ERK kinase), which, in turn, activates ERK via tyrosine and threonine phosphorylation (Robinson et al., 2002). The p44/p42 MAPKs (ERK1/2) are expressed in pancreatic $\beta$ cell and regulate gene transcription and cell differentiation (Lingohr et al., 2002). Glucose, the main insulin secretagogue, induces phosphorylation of cytoplasmic proteins involved in exocytosis of insulin-containing granules such as

\footnotetext{
* Corresponding author. Tel.: +55 11 30917961; fax: +55 1130917285 .

E-mail address: sbordin@icb.usp.br (S. Bordin).
}

synapsin I by activating the ERK1/2 cascade (Longuet et al., 2005).

Prolactin (PRL) upregulates islet function by increasing (1) insulin synthesis; (2) glucose uptake and metabolism; and (3) glucose-induced insulin release with a reduced glucose stimulation threshold (Sorenson et al., 1987a; Sorenson et al., 1987b; Shao et al., 2004). These changes induced by PRL are observed in vivo during early and late pregnancy (Weinhaus et al., 1996). A cDNA array approach was carried out in order to identify new proteins potentially involved in the insulin secretory machinery. We have found that PRL treatment increases ERK3 mRNA and protein content in isolated rat pancreatic islets (Bordin et al., 2004). ERK3 is a distantly related member of the mitogen-activated protein (MAP) kinase superfamily (Pearson et al., 2001; Turgeon et al., 2002). ERK3 is described as a highly unstable protein that is constitutively degraded by the ubiquitin-proteasome pathway in proliferating cells (Coulombe et al., 2003). In the cytoplasm, ERK3 is 
activated by the conventional PKC $\beta$ (Sauma and Friedman, 1996) and targets downstream activation of MAPK-activated protein kinase-5 (MK5) (Seternes et al., 2004; Schumacher et al., 2004).

In this study evidence is presented that ERK3 plays an important role for the functioning of rat pancreatic islet. The following aspects were examined: (i) the regulation of ERK3 expression by PRL during pregnancy, (ii) the distribution of ERK3 among the cell types of the pancreatic islet, (iii) the involvement of ERK3 in the glucose-induced insulin secretion, and (iv) the activation of ERK3 by conventional PKC.

\section{Materials and methods}

\subsection{Materials}

Bovine serum albumin (BSA, fraction V), Ficoll, RPMI-1640 medium, collagenase type $\mathrm{V}$, and the chemicals used in the experiments for immunoblotting were purchased from Sigma (St. Louis, MO, USA). Lipofectamine ${ }^{\mathrm{TM}} 2000$ Transfection Reagent and OPTI-MEM ${ }^{\circledR}$ I Reduced Serum Medium were purchased from Invitrogen (Carlsbad, CA, USA). All plastics for cell culture were obtained from TPP (Trasadingen, Switzerland). Nitrocellulose membranes (Hybond $\mathrm{N}, 0.45 \mu \mathrm{m}$ ), protein A sepharose $6 \mathrm{MB}$, and the enhanced chemiluminescence reagent kit (ECL) were purchased from Amersham Pharmacia Biotech (Uppsala, Sweden). The apparatus for SDS-PAGE and immunoblotting were from Bio-Rad (Richmond, CA, USA). Antibodies against ERK3 (sc-156), MAP2 (sc-20172), and $\alpha$-Tubulin (sc-8035) were from Santa Cruz Technology (Santa Cruz, CA, USA). The antibody against phospho-serine was from Chemicon (Temecula, CA, USA), the anti-ERK1/2 antibody was from Cell Signaling Technology (Beverly, MA, USA) and the anti-PRLR antibody (mouse IgG1 clone U5) was from Affinity Bioreagents (Golden, CO, USA). The PKC inhibitor GÖ-6976 and phorbol-12-myristate-13-acetate (PMA) were from Calbiochem (Darmstadt, Germany). The oligonucleotides for ERK3 knockdown were manufactured by Integrated DNA Technologies (IDT, Coralville, IA, USA).

\subsection{Prolactin receptor PRLR phosphorthioate oligonucleotide treatment and islet isolation}

Phosphorthioate-modified oligonucleotides were designed according to the Genbank accession M74152 from Rattus novergicus PRLR. We have already detailed the treatment, the sequence of the antisense oligo and its in vivo efficiency (Amaral et al., 2004). The experiments presented herein were performed with the same set of animals used in the previous study. Briefly, female Wistar rats were injected (i.p.) with sense (SO-PRLR) and antisense (ASOPRLR) oligonucleotides, respectively, during the 16th, 17th, and 18th days of pregnancy. The rats were killed on the day 19 of pregnancy. For each set of experiments, the islets were isolated from six rats by collagenase digestion of pancreata and separated from pancreatic debris by centrifugation in Ficoll gradient. The experiments involving animals were carried out in accordance with the guidelines of the Brazilian College for Animal Experimentation (COBEA).

\subsection{RNA extraction and RT-PCR}

Total RNA was extracted from approximately 400 islets using Trizol reagent (Invitrogen). Conventional RT-PCR analysis was performed as previously described (Bordin et al., 2004). The amplification products were run on a $1.5 \%$ agarose gel containing ethidium bromide, and the band intensities were determined by digital scanning followed by quantification using the Scion Image analysis software (Scion Corp., Frederick, MD, USA). The results were expressed as a ratio of the target genes to the housekeeping RPL37a. The primer sequences used for RT-PCR analysis with their respective melting point and lengths were as follows: ERK3 sense 5'TGTTGTGAGGTCAGGAAGGACG and antisense $5^{\prime}$ TGTCTTGTGAGGGATTTGAGGG, $57^{\circ} \mathrm{C}, 309 \mathrm{bp}$; RPL37a sense 5'CAAGAAGGTCGGGATCGTCG and antisense 5'ACCAGGCAAGTCTCAGGAGGTG, $57^{\circ} \mathrm{C}, 209 \mathrm{bp}$.

\subsection{Immunostaining}

The animals used for immunolabeling experiments (virgin Wistar female rats) were perfused with saline and $2 \%$ paraformaldehyde in $0.1 \mathrm{M}$ phosphate buffer $(\mathrm{PB})$ under ketamine/xylazine anesthesia and their pancreas postfixed for 5-8 h. After cryoprotection with $30 \%$ sucrose in PB for $48 \mathrm{~h}$, the pancreata were sectioned $(18 \mu \mathrm{m})$ on a cryostat and the sections immediately collected in gelatin and chromoalumen-coated slides. The sections were incubated with a combination of a guinea-pig polyclonal anti-insulin antibody (A-0564 from Dako, Denmark) and a rabbit polyclonal anti-ERK3 antibody (sc-156) from Santa Cruz Technology, both diluted 1:200 in PB with 0.3\% Triton X-100. Following three times of 10 min washes in $\mathrm{PB}$, sections were incubated with a mixture of a donkey anti-guinea-pig IgG labeled with fluorescein isothiocyanate and a donkey anti-rabbit IgG labeled with tetramethyl rhodamine isothiocyanate for $2 \mathrm{~h}$ (Jackson Laboratories, West Grove, PA, USA), both diluted at 1:50 in PB with $0.3 \%$ Triton $\mathrm{X}-100$. Sections were then washed three times for $10 \mathrm{~min}$ in PB and coverslipped with glycerol-carbonate buffer. The material was analyzed under a fluorescence microscope and images captured using a digital camera. For control of immunostaining specificity, primary antibodies were replaced by normal sera.

\subsection{RINm5F cell culture and incubations}

RINm5F cells were cultured as previously described (Wilson et al., 1999). RPMI 1640- $\mathrm{NaHCO}_{3}$ medium supplemented with $10 \%$ bovine fetal serum, $11.1 \mathrm{mM}$ glucose, penicillin $\mathrm{G}(100 \mathrm{IU})$, and streptomycin $\left(100 \mu \mathrm{g} \mathrm{ml}^{-1}\right)$, was used. For immunoprecipitation assay, cells were previously washed for $10 \mathrm{~min}$ at $37^{\circ} \mathrm{C}$ with Krebs-bicarbonate buffer containing $2.8 \mathrm{mM}$ glucose. After that, the cells were incubated in Krebs-bicarbonate buffer containing $2.8 \mathrm{mM}$ glucose and GÖ-6976 $(1 \mu \mathrm{M})$ for $2 \mathrm{~h}$ and then acutely stimulated with PMA $(0.5 \mu \mathrm{M})$ for $20 \mathrm{~min}$

\subsection{Pancreatic islets and RINm5F transient transfection with phosphorthioate oligonucleotide targeted to ERK3}

Pancreatic islets from virgin Wistar rats and RINm5F cells were cultured in Opti-MEM containing $10 \mathrm{mM}$ glucose plus a chimeric DNA-RNA 2'-O-methyl phosphorthioate oligonucleotide targeted to ERK3, previously mixed with Lipofectamine 2000 reagent. Islets and RINm5F cells were treated as follows: (1) with Lipofectamine 2000 reagent only (CTL), (2) with Lipofectamine 2000 mixed with a scrambled oligonucleotide (SO-ERK3), and (3) with Lipofectamine 2000 mixed with an antisense oligonucleotide (ASO-ERK3), and were incubated for $4 \mathrm{~h}$ in serum-deprived media. The medium was then supplemented with fetal bovine serum (10\%) and cultured overnight. Islets and RINm5F cells were then used for insulin secretion assay and conventional immunoblotting against ERK3 to check the efficiency of the blockade. After transfection, RINm5F cells were also acutely stimulated with PMA $(0.5 \mu \mathrm{M}$ for $20 \mathrm{~min})$ and used for MAP2 immunoprecipitation. The sequences of the SO-ERK3 and ASO-ERK3 were, respectively, 5'-mCmAmUmCGGCCCAATGCmCmGmAmC, and 5'mGmCmCmUCCACAGCCCAmAmUmGmG, where ' $m$ ' denotes RNA 2'-Omethyl nucleotides.

\subsection{Insulin secretion}

Groups of five islets were first incubated for $30 \mathrm{~min}$ at $37{ }^{\circ} \mathrm{C}$ in Krebsbicarbonate buffer containing $5.6 \mathrm{mM}$ glucose and equilibrated with $95 \% \mathrm{O}_{2} / 5 \%$ $\mathrm{CO}_{2}, \mathrm{pH}$ 7.4. The solution was then replaced by fresh Krebs-bicarbonate buffer and the islets were incubated for a further $30 \mathrm{~min}$ period with medium containing 5.6 or $11.1 \mathrm{mM}$ glucose.

The RINm5F cells were seeded in 24-well plates and grown to reach near confluency. At the day of the experiment, the cells were first incubated for $30 \mathrm{~min}$ at $37^{\circ} \mathrm{C}$ in Krebs-bicarbonate buffer containing $2.8 \mathrm{mM}$ glucose and equilibrated with $95 \% \mathrm{O}_{2} / 5 \% \mathrm{CO}_{2}, \mathrm{pH}$ 7.4. The solution was then replaced 
with fresh Krebs-bicarbonate buffer and the islets were incubated for a further $1 \mathrm{~h}$ period with medium containing $2.8 \mathrm{mM}$ glucose plus DMSO or PMA.

The cumulative insulin released from islets $(30 \mathrm{~min})$ or RINm5F cells $(1 \mathrm{~h})$ was determined by RIA using rat insulin as standard.

\subsection{Nuclear and cytosolic protein extraction}

RINm5F cells were suspended in $150 \mu l$ of cell lysis buffer $(10 \mathrm{mM}$ Tris, $\mathrm{pH} 8.0,10 \mathrm{mM} \mathrm{NaCl}, 0.2 \%$ Nonidet-P40) containing phosphatase and protease inhibitors (sodium orthovanadate, phenylmethylsulfonyl fluoride, and aprotinin). After $10 \mathrm{~min}$ of incubation on ice, the samples were centrifuged at $2500 \times g$ for $15 \mathrm{~min}$ at $4{ }^{\circ} \mathrm{C}$. The supernatant was removed and used as the cytosolic protein fraction. The pellets of nuclei were suspended in $100 \mu \mathrm{l}$ of nuclear lysis buffer (20 mM Tris, pH 8.0, $10 \mathrm{mM}$ EDTA, $1 \%$ SDS, and phosphatase and protease inhibitors) and incubated on ice for $10 \mathrm{~min}$. The samples were centrifuged at $12,000 \times g$ for $15 \mathrm{~min}$ to remove debris and the supernatant was used as nuclear protein fraction.

\subsection{Protein analysis by Western blotting}

Islets and RINm5F cells were processed for protein extraction as previously described (Amaral et al., 2004). For immunoprecipitation, RINm5F samples were incubated with anti-ERK3 or anti-MAP2 antibodies and processed as previously published (Anhê et al., 2004). Immunoprecipitates and protein samples were resolved in an $8 \%$ SDS-PAGE and transferred to nitrocellulose membrane (Amaral et al., 2004). The membranes were incubated for $4 \mathrm{~h}$ at $22{ }^{\circ} \mathrm{C}$ with antibodies against phospho-serine (1:1000), ERK3 (1:1000), ERK1/2 (1:2000), $\alpha$-Tubulin (1:500), PRLR (1:2000), or MAP2 (1:500) diluted in blocking buffer with $3 \%$ non-fat dried milk, and then washed for $30 \mathrm{~min}$ in blocking buffer without milk. The blots were subsequently incubated with peroxidase-conjugated secondary antibody for $1 \mathrm{~h}$. Visualization of specific protein bands was performed by using the enhanced chemiluminescence reagent kit (ECL, Amersham Pharmacia Biotech) with exposure to photographic film. The band intensities were quantified by optical densitometry (Scion Image, Frederick, MD).

\subsection{Statistical analysis}

Mean values \pm S.E.M. obtained from densitometric scans were compared using Tukey-Kramer test (ANOVA) and the unpaired Student's test when appropriate. $P$-values $<0.05$ indicated significant differences.

\section{Results}

\subsection{Increased ERK3 expression in pancreatic islets from pregnant rats is modulated by $P R L$ receptors}

We have previously demonstrated that isolated pancreatic islets treated with PRL display an increase in ERK3 mRNA and protein levels (Bordin et al., 2004). The present study shows that pancreatic islets freshly isolated from rats on the day 19 of pregnancy also present increased ERK3 expression. The increase in ERK3 expression is observed at the mRNA (by $27 \% ; P<0.05$ ) (Fig. 1A) and at the protein levels (by $200 \% ; P<0.05)$ (Fig. 1B). ERK3 degradation is proposed to be rapidly triggered by the ubiquitin/proteasome proteolytic pathway (Coulombe et al., 2003) and by direct action of caspases (Bind et al., 2004). Since placental lactogen and prolactin are able to downregulate caspase activity (Fernandez et al., 2003; Tessier et al., 2001), the difference between the ERK3 mRNA and protein levels may be a result of reduced ERK3 protein degradation.
In order to confirm the participation of PRL on ERK3 expression during pregnancy, pregnant and virgin rats were treated with a phosphorthioate-modified oligonucleotide targeted to the rat PRLR mRNA sequence. The efficiency of ASO-PRLR treatment to reduce PRLR levels in pancreatic islets from pregnant rats is shown in Fig. 1C. Pregnancy was associated with an increase in ERK3 expression (by 198\%; $P<0.05$ versus CTL treated with SO-PRLR) that was abrogated by PRLR knockdown (by $66 \% ; P<0.05$ versus pregnant treated with SO-PRLR) (Fig. 1D).

\subsection{ERK3 expression in pancreatic islets from adult rats is restricted to $\beta$-cells}

A double-staining immunohistochemical approach using anti-ERK3 and insulin antibodies allowed us to determine the distribution of ERK3 in rat pancreatic islets. Staining overlapped for insulin (green) and for ERK3 (red), indicating that the expression of ERK3 is restricted to the pancreatic $\beta$-cells (Fig. 2).

\subsection{ERK3 knockdown prevents glucose-induced insulin secretion in isolated pancreatic islets and PMA-induced insulin secretion in RINm5F cells}

The PRLR-associated upregulation of ERK3 expression in pancreatic islets of pregnant rats together with the specific localization of ERK3 in the pancreatic $\beta$-cells led us to investigate the participation of ERK3 in the insulin secretory response. Isolated pancreatic islets and RINm5F cells were transfected with chimeric phosphorthioate oligonucleotide targeted to the ERK3 mRNA sequence (Fig. 3A). The control-scrambled oligonucleotide (SO-ERK3) did not interfere with the ERK3 levels whereas the ERK3 ASO promoted a reduction (by $75 \%$ versus CTL and by $60 \%$ versus SO-ERK3; $P<0.05$ ). The antisense oligonucleotide target to the ERK3 sequence was proved to be specific because the protein levels of ERK1/2 remained unchanged (Fig. 3A). Transfection of RINm5F cells exhibited the same efficiency of blockade (data not shown).

Control and SO transfected islets showed an increase in insulin secretion when exposed to $11.1 \mathrm{mM}$ glucose (by $58 \%$ and $57 \%$, respectively; $P<0.05$ versus $5.6 \mathrm{mM}$ glucose). ERK3 blockade abolished the insulin secretion induced by $11.1 \mathrm{mM}$ glucose in rat pancreatic islets but had no effect on $5.6 \mathrm{mM}$ glucose (Fig. 3B).

Although not responsive to glucose, RINm5F cells have been used as a model to study phorbol-12-myristate-13-acetate (PMA)-induced insulin secretion (Wilson et al., 1999; Dunne, 1994). PMA is a potent stimulator of $\beta$-cell insulin secretion (Yaney et al., 2002); the mechanism underlying this effect of PMA relies on its ability to replace DAG in targeting conventional and novel PKC isoforms (Easom et al., 1989). Since ERK3 is likely a downstream target of PKC we tested whether ERK3 could participate in PMA-induced insulin secretion. RINm5F cells untransfected (CTL) and transfected with SO and ASO targeted to ERK3 were then stimulated 
RT-PCR

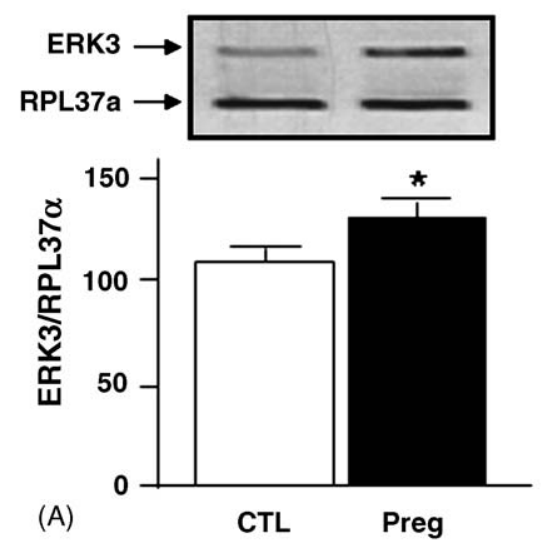

(A)

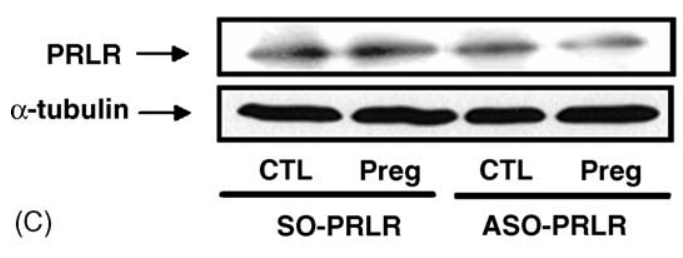

IB: ERK3
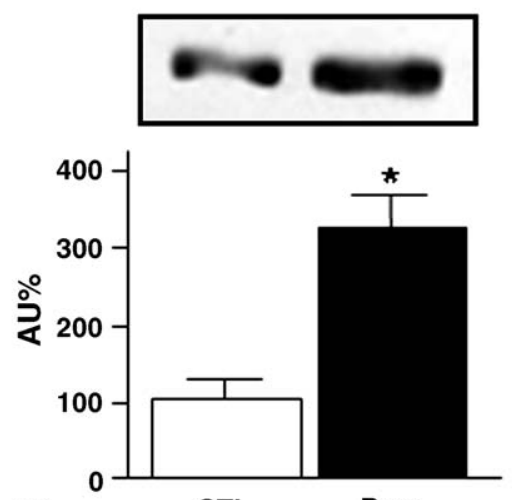

(B)

CTL
Preg

IB: ERK3

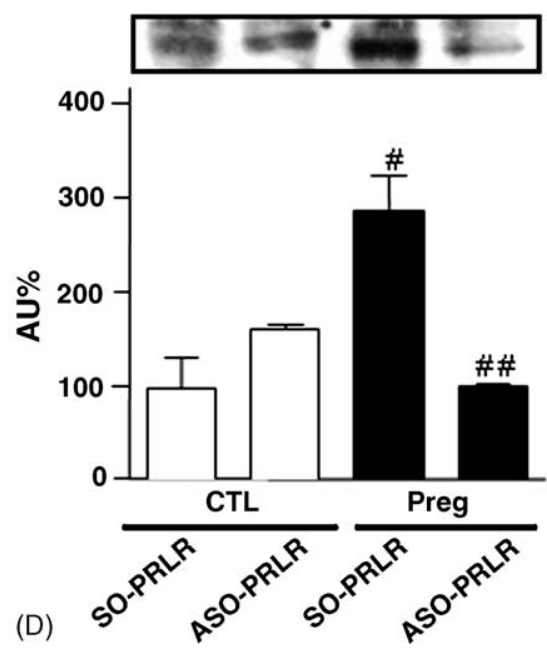

Fig. 1. Expression of ERK3 in rat pancreatic islets and its regulation by prolactin receptor. Islets were isolated from virgin female (CTL) and pregnant (Preg) rats. Total RNA (A) and protein (B) were used for RT-PCR analysis of ERK3 mRNA expression and Western blot analysis of ERK3, respectively. Islets were isolated from pregnant and CTL rats treated with SO-PRLR and ASO-PRLR oligonucleotides targeted to the rat PRL receptor. The protein was extracted and processed for immunobloting against PRLR, $\alpha$-Tubulin (C) and ERK3 (D). The bars represent the relative expression of ERK3 as determined by optical densitometry and are presented as mean \pm S.E.M. ${ }^{*} P<0.05$ vs. CTL. ${ }^{\#} P<0.05$ vs. CTL + SO-PRLR. ${ }^{\# \#} P<0.05$ vs. Pregnant + SO-PRLR.

with PMA $0.5 \mu \mathrm{M}$ to assay insulin secretion. Both CTL and SO transfected cells exhibited an increase in insulin secretion in the presence of PMA (by $131 \%$ and $196 \%$, respectively; $P<0.05$ versus $2.8 \mathrm{mM}$ glucose without PMA). This incre- ment was abolished by ERK3 knockdown in ASO transfected cells. Neither the SO nor the ASO transfected cells showed any difference in basal (glucose $2.8 \mathrm{mM}$ ) insulin secretion (Fig. 3C).

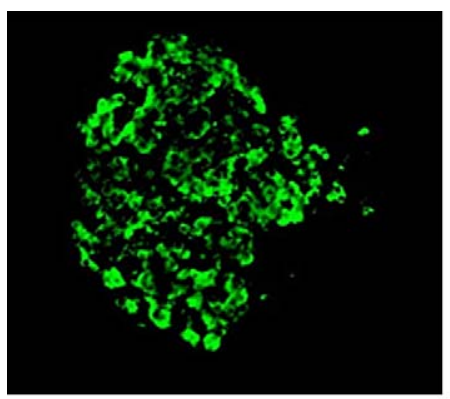

Insulin

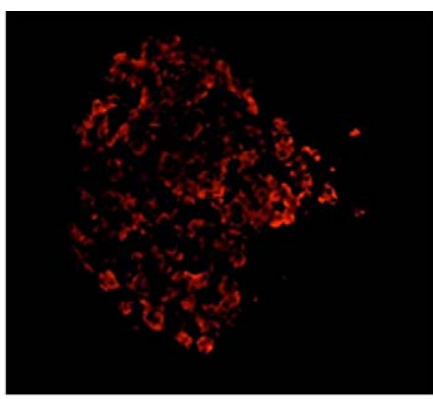

ERK3

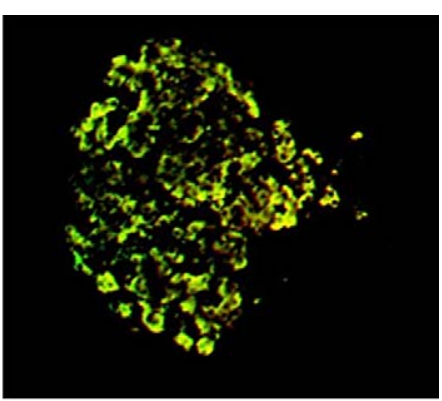

Insulin/ERK3

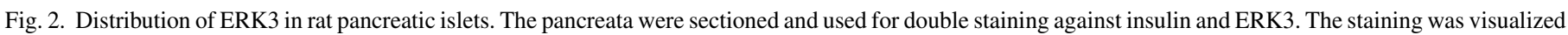

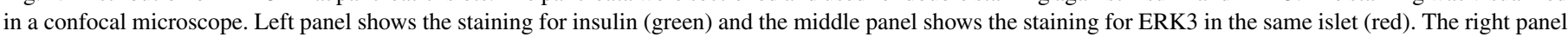
represents the overlapping of both images (yellow). 

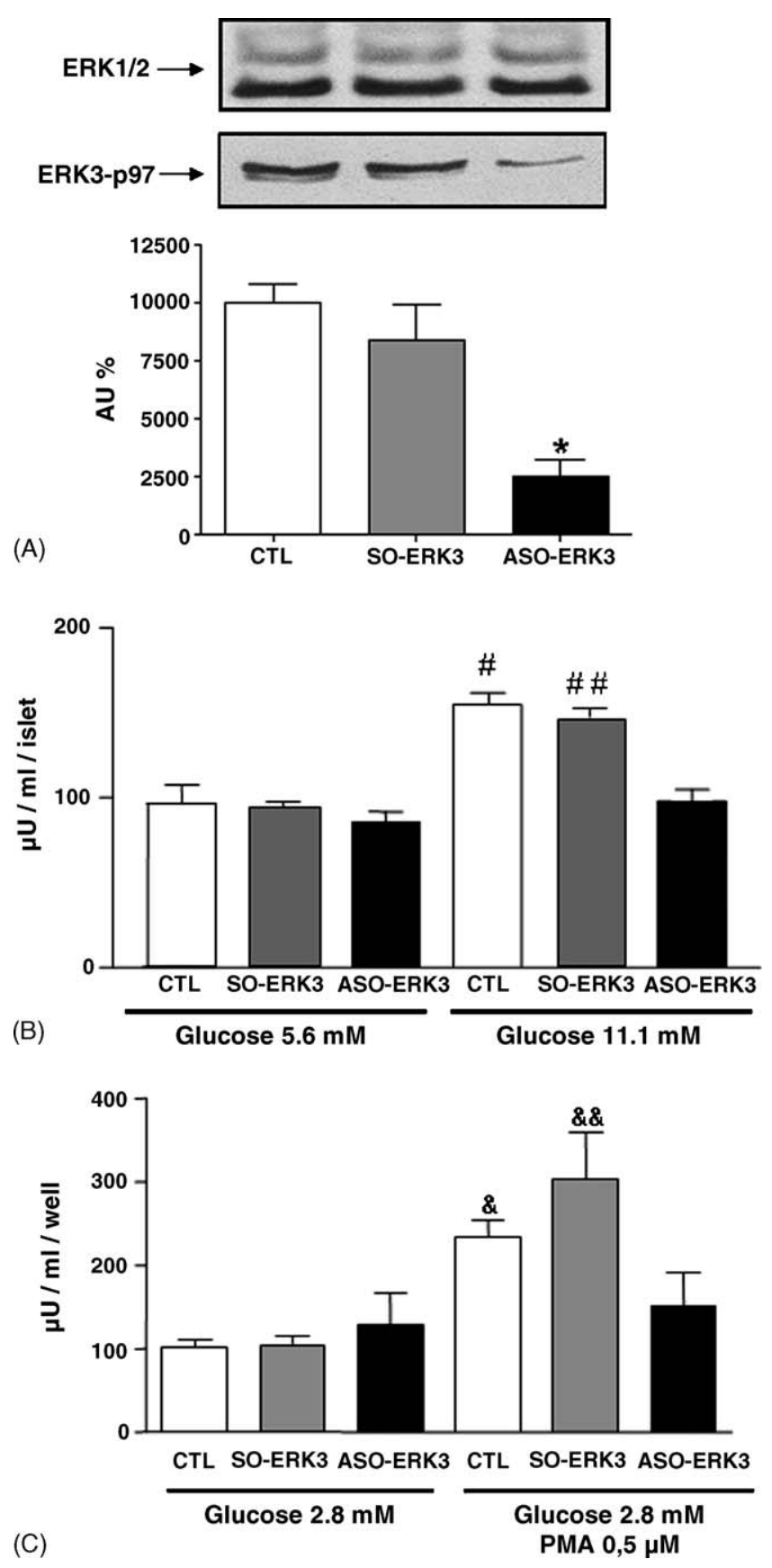

Fig. 3. Participation of ERK3 in insulin secretion by pancreatic islets and RINm5F cells. (A) Groups of 150-200 pancreatic islets from rats (CTL) were cultured overnight and transiently transfected with scrambled (SO-ERK3) or antisense (ASO-ERK3) oligonucleotides against ERK3. After $24 \mathrm{~h}$ of culture, islets were used for immunobloting against ERK3 (B) or insulin secretion assay (C) RINm5F cells were grown in 24-well plates to $10^{5}$ cells/well and transiently transfected with scrambled (SO-ERK3) or antisense (ASO-ERK3) oligonucleotides against ERK3. After $24 \mathrm{~h}$ of culture the cells were used for insulin secretion assay. The results represent the relative expression of ERK3 as determined by optical densitometry for the immunobloting and the cumulative insulin secretion during $30 \mathrm{~min}$ (islets) or $1 \mathrm{~h}$ (RINm5F cells), and are presented as mean \pm S.E.M. ${ }^{*} P<0.05$ vs. CTL and SO-ERK3. ${ }^{\#} P<0.05$ vs. CTL in $5.6 \mathrm{mM}$ glucose. ${ }^{\# \#} P<0.05$ vs. SO-ERK3 in $5.6 \mathrm{mM}$ glucose. ${ }^{\circledR} P<0.05$ vs. CTL in $2.8 \mathrm{mM}$ glucose without PMA. ${ }^{\&} \& P<0.05$ vs. SO-ERK3 in $2.8 \mathrm{mM}$ glucose without PMA.

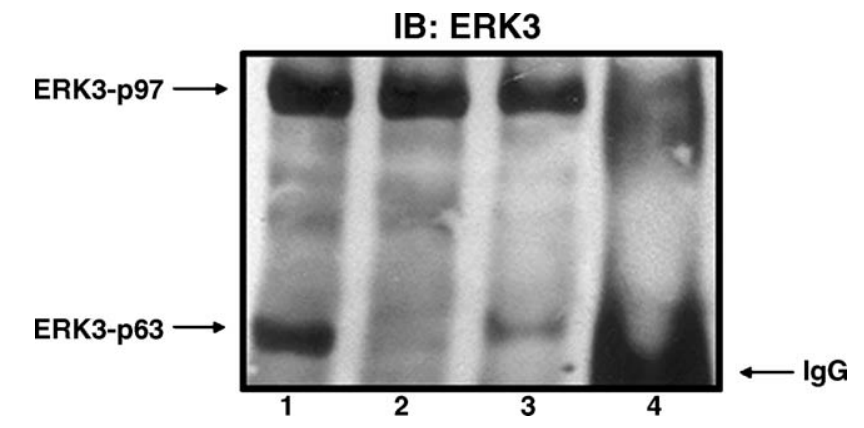

Fig. 4. Localization of ERK3 isoforms in RINm5F cells. Total (1), cytoplasmatic (2), and nuclear (3) fractions from protein extract of RINm5F cells were resolved in $8 \%$ SDS-PAGE together with the protein eluted from MAP2 immunoprecipitates (4) (see Section 2). The membrane was probed with anti-ERK3 antibody.

\subsection{ERK3 distribution in RINm5F cell compartments and $P M A$-stimulated ERK3 serine phosphorylation and association with microtubule-associated protein 2 (MAP2)}

A recent study reported that rat ERK3 has nuclear $(\sim 63 \mathrm{kDa})$ and cytoplasmic ( $\sim 97 \mathrm{kDa})$ forms. Rat insulinoma lineage RINm5F cells contain both forms of ERK3 (Fig. 4). As reported for other cell types (Bind et al., 2004), p63-ERK3 is an exclusive nuclear form of this MAPK and it is not found in the cytosolic fraction. The p97-ERK3 is detected in both cytoplasmic and nuclear fractions. It is possible that the presence of p97-ERK3 in the nuclear fraction results from an active nuclear import (Julien et al., 2003). Additionally, p97-MAP2 associates with the microtubule-associated protein 2 (MAP2) (Fig. 4).

MAP2 is a member of a larger family of microtubuleassociated proteins that, upon phosphorylation, have the ability to regulate reversible polymerization and stability of microtubules through their affinity for tubulin (Sloboda et al., 1976) as well as their interaction with other cellular structures such as actin (Sattilaro, 1986). MAP Kinases such as JNK and ERK1/2 have been reported to associate with and consequently phosphorylate MAP2 (Chang et al., 2003; Cobb et al., 1991). Attempting to find out a possible mechanism to explain ERK3 participation in insulin secretion we tested whether PMA could promote ERK3 serine phosphorylation and association with MAP2.

PMA induced an increase in ERK3 serine phosphorylation (by $40 \% ; P<0.05$ ). This effect was abolished by addition of the PKC inhibitor GÖ-6976. The increase in ERK3 phosphorylation was not associated with changes in ERK3 content (Fig. 5A). Together with ERK3 phosphorylation, PMA was able to induce PKC dependent ERK3/MAP2 association (an increase of 60\%; $P<0.05$ ) (Fig. 5B).

\subsection{ERK3 knockdown blockades PMA-induced MAP2 serine phosphorylation in RINm5F cells}

MAP2 is efficiently phosphorylated in serine residues by several classes of Ser/Thr protein kinases in vitro, including cAMPdependent protein kinase (PKA) (Sloboda et al., 1975), MAPKinases, such as ERK1/2 (Quinlan and Shelley, 1996; Sanchez et al., 1995) and protein kinase C (PKC) (Walaas and Nairn, 1989). Considering the above results showing ERK3 phosphorylation 

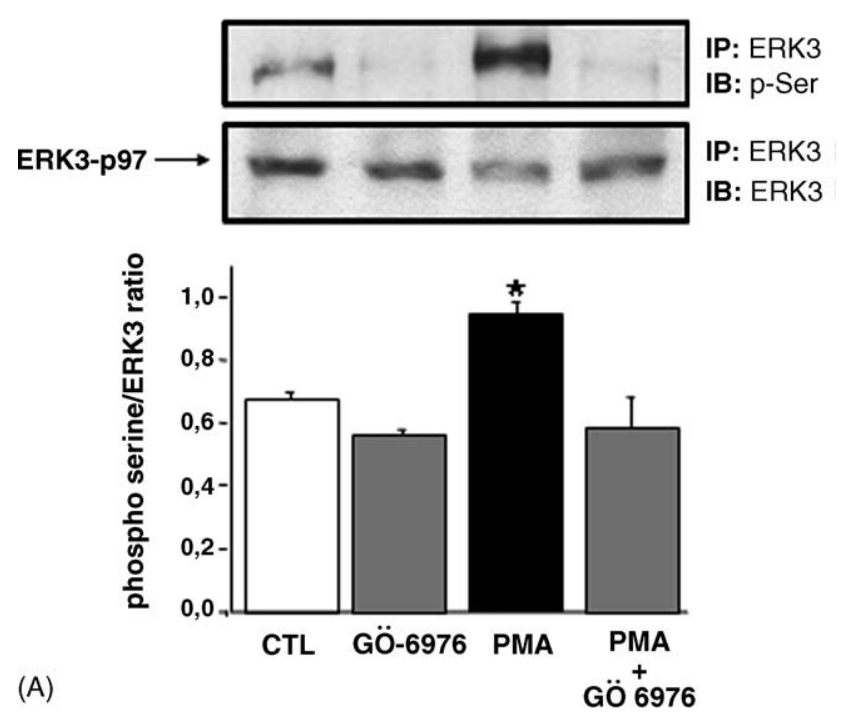

(A)

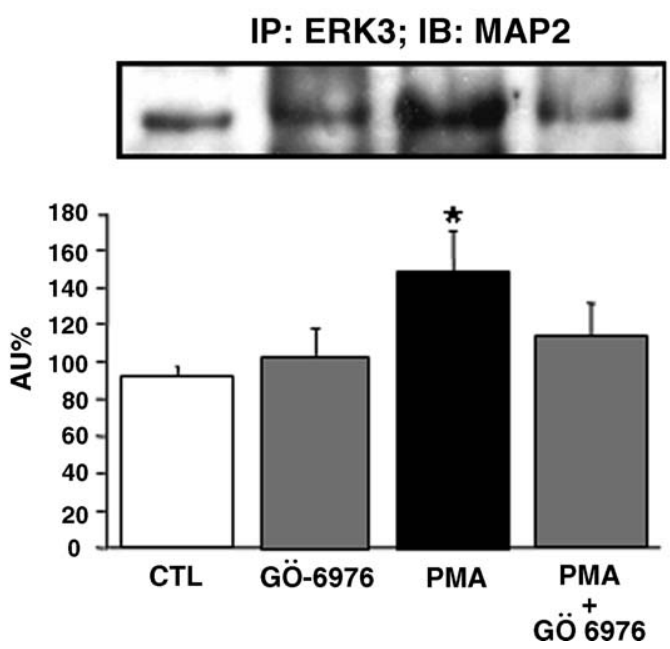

Fig. 5. PMA-induced p97-ERK3 serine phosphorylation and association with MAP2. RINm5F cells were incubated in Krebs-bicarbonate buffer $(2.8 \mathrm{mM}$ glucose) and the vehicle 0.3\% DMSO or the PKC inhibtor GÖ-6976 (0.5 $\mu \mathrm{M})$. After $1 \mathrm{~h}$, the solution was replaced by fresh medium for $30 \mathrm{~min}$ with $0.3 \%$ DMSO or $0.5 \mu$ M PMA (PMA). Cell extracts were processed for ERK3 immunoprecipitation (Section 2). The membranes were probed with anti-phospho-serine, anti-ERK3 (A) and anti-MAP2 (B) antibodies. The results are presented as mean \pm S.E.M. and represent the relative phosphorylation of ERK3 and the amount of MAP2 associated with ERK3. ${ }^{*} P<0.05$ vs. CTL, GÖ-6976, and PMA + GÖ-6976.

and association with MAP2 after conventional PKC activation by PMA, we investigated whether ERK3 could mediate PMAinduced MAP2 serine phosphorylation. PMA induced MAP2 serine phosphorylation in RINm5F cells (Fig. 6). This effect is completely blocked by the knockdown of ERK3 expression.

\section{Discussion}

Pregnancy induces peripheral insulin resistance, which is normally compensated by increased $\beta$ cell proliferation, expansion of islet volume, and increased insulin synthesis and secretion. Several experiments performed both in vitro and in vivo have shown that lactogenic hormone treatment induces the same changes in islets as those observed during pregnancy (Sorenson
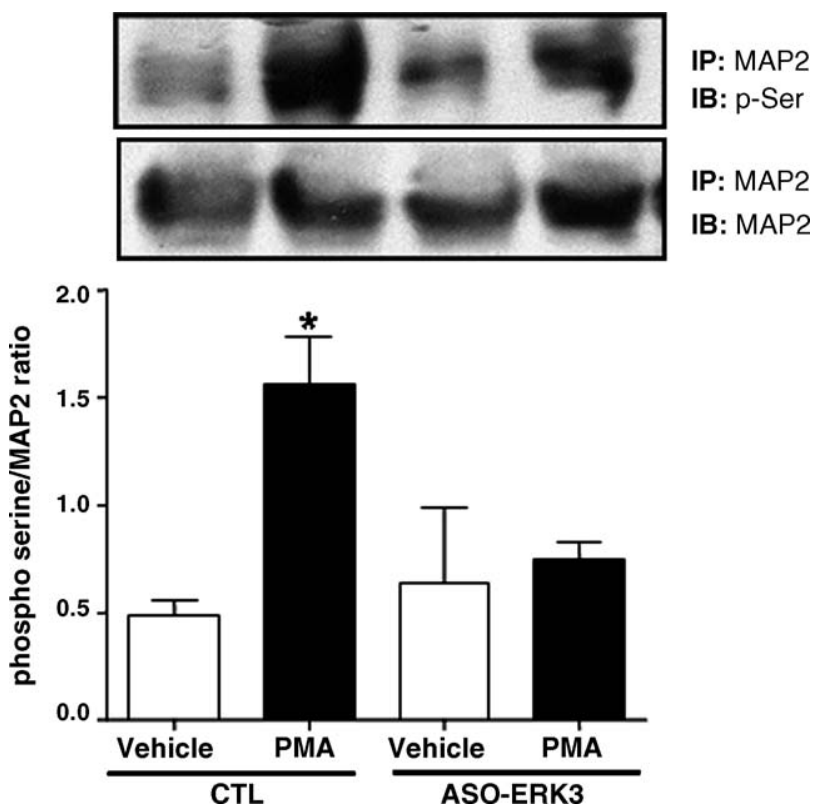

Fig. 6. ERK3 knockdown blockades PMA-induced MAP2 serine phosphorylation. RINm5F cells were transiently transfected with antisense (ASO-ERK3) oligonucleotides against ERK3. After $24 \mathrm{~h}$ of culture, untransfected and ASOERK3 transfected cells were incubated in Krebs-bicarbonate buffer $(2.8 \mathrm{mM}$ glucose) for $20 \mathrm{~min}$ containing the vehicle $0.3 \%$ DMSO or $0.5 \mu \mathrm{M}$ PMA. Cell extracts were processed for MAP2 immunoprecipitation. The membranes were probed with anti-phospho-serine and anti-MAP2 antibodies. The results are presented as mean \pm S.E.M. and represent the relative phosphorylation of MAP2 ${ }^{*} P<0.05$ vs. CTL treated with the vehicle.

et al., 1987a; Sorenson et al., 1987b; Nielsen et al., 1999). The present results show for the first time that PRL regulates ERK3 expression in an in vivo model of increased insulin secretion. PRL regulation of ERK3 expression and its specific location in pancreatic $\beta$ cells led us to investigate the participation of ERK3 in the insulin secretion process.

ERK1 and ERK2 are activated by phosphorylation on tyrosine and threonine by a well known pathway through MEK and MEK Kinase (Seger and Krebs, 1995). In contrast, ERK3 is the unique MAPK that contains a single phosphorylation site (serine 189) in its activation loop (Prowse and Lew, 2001). Information regarding upstream activation of ERK3 shows that this MAPK seems to be activated by conventional PKC $\beta$ (Sauma and Friedman, 1996). Considering the present results that ERK3 knockdown abolished both glucose and PMA-induced insulin secretion by pancreatic $\beta$ cells, it is likely that ERK3 plays an important role in the glucose-induced insulin secretion through PKC activation.

Although both human and mouse ERK3 proteins have essentially identical amino acid sequence encoding a 721-amino acid protein of approximately $100 \mathrm{kDa}$ (Zhu et al., 1994), the rat orthologue ERK3 gene was first reported to encode a unique 62$\mathrm{kDa}$ protein containing 543 amino acids (Boulton et al., 1991) Recently, in vitro translation of the rat and human ERK3 cDNAs reconciled the rat protein sequence with that of the mouse and human and revealed that both genes encoded proteins of the same molecular weight $( \pm 100 \mathrm{kDa})$ (Bind et al., 2004). Information regarding subcellular localization was also initially controver- 
sial. An initial study described ERK3 as a constitutively nuclear protein kinase (Cheng et al., 1996). A later report however demonstrated that the $100 \mathrm{kDa}$ endogenous rat and human ERK3 is a Golgi-resident cytoplasmic protein, whereas the nuclear form of ERK3 is likely to be between 45 and $68 \mathrm{kDa}$ that results from the degradation of the heavier isoform (Bind et al., 2004). Our Western blot analysis showed the presence of both nuclear and cytoplasmic ERK3 isoforms in rat pancreatic $\beta$ cells. The cytoplasmic ERK3 isoform is phosphorylated on serine residues via conventional PKC activation. In addition to the increased ERK3 phosphorylation by PKC, the present results also show that the stimulation of conventional PKC pathway increases the phosphorylation of MAP2 associated with ERK3. Therefore, the complex ERK3/MAP2 formed after PMA stimulus might play an important part for the mechanism by which ERK3 modulates insulin secretion.

The acronym MAPKs is derived not only from mitogenactivated protein kinases but also from microtubule-associated protein kinases. MAPKs were initially discovered in association with the cytoskeleton and were later found to be implicated in the regulation of nuclear transcript events. In insulin-secreting cells, the best studied MAPKs ERK1/2 are activated by high glucose concentrations. However, a close relationship between ERK1/2 activity and insulin release has not been consistently demonstrated. First, stimulation of insulin secretion after glucoseinduced ERK1/2 activation varies among different types of $\beta$ cell lineages (Khoo and Cobb, 1997; Benes et al., 1998; Longuet et al., 2005). Second, in pancreatic islets, ERK1/2 phosphorylation is completely prevented by the treatment with the selective MEK inhibitor PD98059, whereas insulin response is partially reduced (Longuet et al., 2005). Considering the findings that ERK1/2 are activated by stimuli that do not elicit secretion (Frodin et al., 1995), and that the increase in ERK1/2 activity is related to the induction of several genes, including insulin (Frodin et al., 1995; Benes et al., 1999), it is likely that the transcriptional machinery is the most relevant target of ERK1/2. Thus, the abolition of glucose- and PMA-stimulated insulin secretion after ERK3 knockdown showed herein support the proposition that ERK3, instead of ERK1/2, is a MAPK preferentially involved in the process of insulin-containing granule exocytosis.

It is well known that the regulation of microtubule polymerization is directly mediated by a large family of microtubuleassociated proteins (MAPs) (Desai and Mitchison, 1997). Microtubules often undergo rapid transitions between stable and dynamic forms as a result of continuous growing and shrinking of their ends. This phenomenon, termed dynamic instability, regulates several cellular processes such as intracellular transport, cell motility, mitosis, and differentiation (Kirschner and Mitchison, 1986). The involvement of microtubule-dependent $\beta$ cell secretory activity has been well established (Lacy et al., 1972; Pipeleers et al., 1976; Somers et al., 1979), and the participation of MAPs in the insulin secretion process is supported by the evidence that isolated insulin-containing secretory granules interact with microtubules in the presence of exogenous MAPs only (Suprenant and Dentler, 1982). It has been proposed that the activation of CaM kinase II, a multifunctional $\mathrm{Ca}^{2+} /$ calmodulin-dependent protein kinase, is stimulated by glu- cose and modulates insulin secretion by activation of MAP-2 and synapsin-1 (Easom, 1999), but the regulation of the molecular motor activity during insulin-containing granules exocytosis is poorly understood.

The microtubule-associated protein MAP2 is efficiently phosphorylated by several protein kinases, including MAPKs (Karin, 1995; Gupta et al., 1996), as observed for the JNK family. Following activation, a portion of the activated JNK enters the nucleus, resulting in phosphorylation of several transcription factors, including c-Jun, ATF-2, and Elk-1 (Chang et al., 2003; Cobb et al., 1991). However, another pool of JNK (mainly JNK1) directly phosphorylates and activates MAP2 and MAP1b, which result in modulation of microtubule dynamics. The ability of JNK to phosphorylate MAP2 is additionally supported by JNK1/MAP2 co-immunoprecipitation (Chang et al., 2003). MAPK signaling to MAPs is also involved in regulation of cytoskeleton in nonneuronal cells in various conditions (Minshull et al., 1994; Takenaka et al., 1998) but the mechanisms underlying this function of MAPKs is still unclear.

Various studies have shown that overexpression of MAPs in fibroblasts and neurons causes inhibition of plus-end-directed microtubule transport (Mandelkow et al., 2004). For instance, mitochondria accumulate within the cell body and its movement through the axons is impaired when tau protein is overexpressed. Other MAPs such as MAP4 and MAP2c similarly inhibit motor-based transport, with the severity of the inhibition being correlated with the strength of the binding affinity of the particular MAP. Mandelkow et al. (2004) have shown that overexpression of the microtubule affinity regulating kinase MARK causes phosphorylation of MAPs, which in turn impairs their association with microtubules. Inhibition of transport by overexpression of tau is then relieved by MARK overexpression. Based on these observations, Baas and Qiang (2005) hypothesized that the levels of various cytoskeletal proteins and relevant kinases might regulate MAPs by phosphorylation and then determine the frequency by which motor-based transport events occur within the microtubule. We therefore propose that ERK3 might act as dominant kinase for MAP2 in pancreatic $\beta$ cell, inasmuch its phosphorylation is accompanied by its association with MAP2, and ERK3 knockdown markedly reduced PMA-induced MAP2 phosphorylation and, consequently, insulin secretion.

Our study is not the first to correlate MAP2 with insulin secretion. Krueger et al. (1997) have shown that different isoforms of MAP2 are expressed in pancreatic islets. The highmolecular mass form of MAP2 is preferentially expressed in rat insulinoma $\beta$ TC 3 cells, and is positively regulated by $\mathrm{Ca}^{2+}$ and $\mathrm{CaM}$ kinase II. In the present study, the expression of the small MAP2 isoform termed MAP2c was observed, probably due to the specificity of the antibody used. Krueger et al. (1997) showed the presence of an unidentified phosphoprotein co-immunoprecipitated with the large MAP2 that has identical migration pattern observed in our experiments. The phosphorylation status of this small co-immunoprecipitated protein is also regulated by $\mathrm{Ca}^{2+}$ in a time- and concentration-dependent manner. Based on these observations, we do not exclude the participation of other MAP2 isoforms in ERK3-mediated insulin secretion. 
In summary, our study is the first to show that ERK3 expression is modulated by PRL in an in vivo model of increased insulin secretion. We also describe the presence of ERK3 in pancreatic $\beta$-cells and demonstrate its involvement in glucoseand PMA-induced insulin release. Additionally, we propose a possible mechanism for the ERK3 participation in pancreatic islet physiology. This mechanism involves activation of the conventional PKC leading to ERK3 serine phosphorylation and association with MAP2. The expression of ERK3, and possibly the formation of the ERK3/MAP2 complex, is necessary for MAP2 phosphorylation after PKC activation.

\section{Acknowledgements}

This work was supported by the Brazilian foundations FAPESP, CAPES, and CNPQ/PRONEX. The authors thank Ribeiro L.M., Scialfa-Falcão J.H., Lima M.A.S., Barbosa H.C., and Rocha M.S. for technical assistance and Dr. Cipolla-Neto J. for kindly permitting the use of his laboratory.

\section{References}

Amaral, M.E., Cunha, D.A., Anhê, G.F., Ueno, M., Carneiro, E.M., Velloso, L.A., Bordin, S., Boschero, A.C., 2004. Participation of prolactin receptors and phosphatidylinositol 3-kinase and MAP kinase pathways in the increase in pancreatic islet mass and sensitivity to glucose during pregnancy. J. Endocrinol. 183, 469-476.

Anhê, G.F., Caperuto, L.C., Pereira-Da-Silva, M., Souza, L.C., Hirata, A.E., Velloso, L.A., Cipolla-Neto, J., Carvalho, C.R., 2004. In vivo activation of insulin receptor tyrosine kinase by melatonin in the rat hypothalamus. J. Neurochem. 9, 559-566.

Baas, P.W., Qiang, L., 2005. Neuronal microtubules: when the MAP is the roadblock. Trends Cell Biol. 15, 183-187.

Benes, C., Poitout, V., Marie, J.C., Martin-Perez, J., Roisin, M.P., Fagard, R., 1999. Mode of regulation of the extracellular signal-regulated kinases in the pancreatic beta-cell line MIN6 and their implication in the regulation of insulin gene transcription. Biochem. J. 340, 219-225.

Benes, C., Roisin, M.P., Van Tan, H., Creuzet, C., Miyazakim, J., Fagardm, R., 1998. Rapid activation and nuclear translocation of mitogen-activated protein kinases in response to physiological concentration of glucose in the MIN6 pancreatic beta cell line. J. Biol. Chem. 273, 1550715513.

Bind, E., Kleyner, Y., Skowronska-Krawczyk, D., Bien, E., Dynlacht, B.D., Sanchez, I., 2004. A novel mechanism for mitogen-activated protein kinase localization. Mol. Biol. Cell. 15, 4457-4466.

Bordin, S., Amaral, M.E., Anhê, G.F., Delghingaro-Augusto, V., Cunha, D.A., Nicoletti- Carvalho, J.E., Boschero, A.C., 2004. Prolactin-modulated gene expression profiles in pancreatic islets from adult female rats. Mol. Cell. Endocrinol. 220, 41-50.

Boulton, T.G., Nye, S.H., Robbins, D.J., Ip, N.Y., Radziejewska, E., Morganbesser, S.D., Depinho, R.A., Panayotatos, N., Cobb, M.H., Yancopoulos, G.D., 1991. ERKs: a family of protein-serine/threonine kinases that are activated and tyrosine phosphorylated in response to insulin and NGF. Cell 65, 663-675.

Chang, L., Jones, Y., Ellisman, M.H., Goldstein, L.S., Karin, M., 2003. JNK1 is required for maintenance of neuronal microtubules and controls phosphorylation of microtubule-associated proteins. Dev. Cell. 4, 521-533.

Cheng, M., Boulton, T.G., Cobb, M.H., 1996. Erk3 is a constitutively nuclear kinase. J. Biol. Chem. 271, 8951-8958.

Cobb, M.H., Robbins, D.J., Boulton, T.G., 1991. ERKs, extracellular signalregulated MAP-2 kinases. Curr. Opin. Cell. Biol. 3, 1025-1032.

Coulombe, P., Rodier, G., Pelletier, S., Pellerin, J., Meloche, S., 2003. Rapid turnover of extracellular signal-regulated kinase 3 by the ubiquitin-proteasome pathway defines a novel paradigm of mitogen- activated protein kinase regulation during cellular differentiation. Mol. Cell. Biol. 23, 4542-4558.

Desai, A., Mitchison, T.J., 1997. Microtubule polymerization dynamics. Annu. Rev. Cell. Dev. Biol. 13, 83-117.

Dunne, M.J., 1994. Phorbol myristate acetate and ATP-sensitive potassium channels in insulin-secreting cells. Am. J. Physiol. 267, 501-506.

Easom, R.A., 1999. CaM kinase II: a protein kinase with extraordinary talents germane to insulin exocytosis. Diabetes 48, 675-684.

Easom, R.A., Hughes, J.H., Landt, M., Wolf, B.A., Turk, J., McDaniel, M.L., 1989. Comparison of effects of phorbol esters and glucose on protein kinase $\mathrm{C}$ activation and insulin secretion in pancreatic islets. Biochem. $\mathrm{J}$. 264, 27-33.

Fernandez, M.L., Iglesias, M.M., Biron, V.A., Wolfenstein-Todel, C., 2003. Protective effect of prolactin and placental lactogen on NO-induced $\mathrm{Nb} 2$ lymphoma cell apoptosis. Arch. Biochem. Biophys. 416, 249-456.

Frodin, M., Sekine, N., Roche, E., Filloux, C., Prentki, M., Wollheim, C.B., Van Obberghen, E., 1995. Glucose, other secretagogues, and nerve growth factor stimulate mitogen-activated protein kinase in the insulin-secreting beta-cell line, INS-1. J. Biol. Chem. 270, 7882-7889.

Gupta, S., Barrett, T., Whitmarsh, A.J., Cavanagh, J., Sluss, H.K., Derijard, B., Davis, R.J., 1996. Selective interaction of JNK protein kinase isoforms with transcription factors. EMBO J. 15, 2760-2770.

Julien, C., Coulombe, P., Sylvain Meloche, S., 2003. Nuclear export of ERK3 by a CRM1-dependent mechanism regulates its inhibitory action on cell cycle progression. J. Biol. Chem. 278, 42615-42624.

Karin, M., 1995. The regulation of AP-1 activity by mitogen-activated protein kinases. J. Biol. Chem. 270, 16483-16486.

Khoo, S., Cobb, M.H., 1997. Activation of mitogen-activating protein kinase by glucose is not required for insulin secretion. Proc. Natl. Acad. Sci. U.S.A. 94, 5599-5604.

Kirschner, M.W., Mitchison, T., 1986. Microtubule dynamics. Nature 324, 621.

Krueger, K.A., Bhatt, H., Landt, M., Easom, R.A., 1997. Calcium-stimulated phosphorylation of MAP-2 in pancreatic betaTC3-cells is mediated by $\mathrm{Ca}^{2+} /$ calmodulin-dependent kinase II. J. Biol. Chem. 272, 27464-27469.

Lacy, P.E., Walker, M.M., Fink, C.J., 1972. Perifusion of isolated rat islets in vitro Participation of the microtubular system in the biphasic release of insulin. Diabetes 21, 987-998.

Lingohr, M.K., Dickson, L.M., McCuaig, J.F., Hugl, S.R., Twardzik, D.R., Rhodes, C.J., 2002. Activation of IRS-2-mediated signal transduction by IGF-1, but not TGF-alpha or EGF, augments pancreatic $\beta$-cell proliferation. Diabetes 51, 966-976.

Longuet, C., Broca, C., Costes, S., Hani, E.H., Bataille, D., Dalle, S., 2005. Extracellularly regulated kinases $1 / 2$ (p44/42 mitogen-activated protein kinases) phosphorylate synapsin I and regulate insulin secretion in the MIN6 beta-cell line and islets of Langerhans. Endocrinology 146, 643-654.

Mandelkow, E.M., Thies, E., Trinczek, B., Biernat, J., Mandelkow, E., 2004. MARK/PAR1 kinase is a regulator of microtubule-dependent transport in axons. J. Cell Biol. 167, 99-110.

Minshull, J., Sun, H., Tonks, N.K., Murray, A.W., 1994. A MAP kinasedependent spindle assembly checkpoint in Xenopus egg extracts. Cell 79, 475-486.

Nielsen, J.H., Svensson, C., Galsgaard, E.D., Moldrup, A., Billestrup, N., 1999. Beta cell proliferation and growth factors. J. Mol. Med. 77, 62-66.

Pearson, G., Robinson, F., Beers, G.T., Xu, B.E., Karandikar, M., Berman, K., Cobb, M., 2001. Mitogen-activated protein (MAP) kinase pathways: regulation and physiological functions. Endocr. Rev. 22, 153-183.

Pipeleers, D.G., Pipeleers-Marichal, M.A., Kipnis, D.M., 1976. Microtubule assembly and the intracellular transport of secretory granules in pancreatic islets. Science 191, 88-90.

Prowse, C.N., Lew, J., 2001. Mechanism of activation of ERK2 by dual phosphorylation. J. Biol. Chem. 276, 99-103.

Quinlan, E.M., Shelley, H., 1996. Emergence of activity-dependent bidirectional control of microtubule-associated protein MAP2 phosphorylation during postnatal development. J. Neurosci. 16, 7627-7637.

Robinson, M.J., Xu Be, B.E., Stippec, S., Cobb, M.H., 2002. Different domains of the mitogen-activated protein kinases ERK3 and ERK2 direct 
subcellular localization and upstream specificity in vivo. J. Biol. Chem. 277, 5094-5100.

Sanchez, C., Diaz-Nido, J., Avila, J., 1995. Variations in in vivo phosphorylation at the proline-rich domain of the microtubule-associated protein 2 (MAP2) during rat brain development. Biochem. J. 306, 481487.

Sattilaro, R.F., 1986. Interaction of microtubule-associated protein 2 with actin filaments. Biochemistry 25, 2003-2009.

Sauma, S., Friedman, E., 1996. Increased expression of protein kinase C beta activates ERK3. J. Biol. Chem. 271, 11422-11426.

Schumacher, S., Laass, K., Kant, S., Shi, Y., Visel, A., Gruber, A.D., Kotlyarov, A., Gaestel, M., 2004. Scaffolding by ERK3 regulates MK5 in development. EMBO J. 23, 4770-4779.

Seger, R., Krebs, E.G., 1995. The MAPK signaling cascade. FASEB J. 9, 726-735.

Seternes, O.M., Mikalsen, T., Johansen, B., Michaelsen, E., Armstrong, C.G., Morrice, N.A., Turgeon, B., Meloche, S., Moens, U., Keyse, S.M., 2004. Activation of MK5/PRAK by the atypical MAP kinase ERK3 defines a novel signal transduction pathway. EMBO J. 23, 47804791.

Shao, J., Qiao, L., Friedman, J.E., 2004. Prolactin, progesterone, and dexamethasone coordinately and adversely regulate glucokinase and cAMP/PDE cascades in MIN6 beta-cells. Am. J. Physiol. Endocrinol. Metab. 286, 304-310.

Sloboda, R., Dentler, W., Rosenbaum, J., 1976. Microtubule-associated proteins and the stimulation of tubulin assembly in vitro. Biochemistry 15 , $4497-4505$.

Sloboda, R.D., Rudolph, S.A., Rosenbaum, J.L., Greengard, P., 1975. Cyclic AMP-dependent endogenous phosphorylation of a microtubule-associated protein. Proc. Natl. Acad. Sci. U.S.A. 72, 177-181.

Somers, G., Blondel, B., Orci, L., Malaisse, W.J., 1979. Motile events in pancreatic endocrine cells. Endocrinology 104, 255-264.

Sorenson, R.L., Brelje, T.C., Hegre, O.D., Marshall, S., Anaya, P., Sheridan, J.D., 1987a. Prolactin (in vitro) decreases the glucose stimulation threshold, enhances insulin secretion, and increases dye coupling among islet B cells. Endocrinology 121, 1447-1453.
Sorenson, R.L., Johnson, M.G., Parsons, J.A., Sheridan, J.D., $1987 b$. Decreased glucose stimulation threshold, enhanced insulin secretion, and increased beta cell coupling in islets of prolactin-treated rats. Pancreas 2, 283-288.

Suprenant, K.A., Dentler, W.L., 1982. Association between endocrine pancreatic secretory granules and in-vitro-assembled microtubules is dependent upon microtubule-associated proteins. J. Cell. Biol. 93, 164-174.

Takenaka, K., Moriguchi, T., Nishida, E., 1998. Activation of the protein kinase $\mathrm{p} 38$ in the spindle assembly checkpoint and mitotic arrest. Science 280, 599-602.

Tessier, C., Prigent-Tessier, A., Ferguson-Gottschall, S., Gu, Y., Gibori, G., 2001. PRL antiapoptotic effect in the rat decidua involves the PI3K/protein kinase B-mediated inhibition of caspase-3 activity. Endocrinology 142, 4086-4094.

Turgeon, B., Lang, B.F., Meloche, S., 2002. The protein kinase ERK3 is encoded by a single functional gene: genomic analysis of the ERK3 gene family. Genomics 80, 673-680.

Walaas, S.I., Nairn, A.C., 1989. Multisite phosphorylation of microtubuleassociated protein 2 (MAP-2) in rat brain: peptide mapping distinguishes between cyclic AMP-, calcium/calmodulin-, and calcium/phospholipidregulated phosphorylation mechanisms. J. Mol. Neurosci. 1, 117-127.

Weinhaus, A.J., Stout, L.E., Sorenson, R.L., 1996. Glucokinase, hexokinase, glucose transporter 2, and glucose metabolism in islets during pregnancy and prolactin-treated islets in vitro: mechanisms for long term up-regulation of islets. Endocrinology 137, 1640-1649.

Wilson, J.R., Biden, T.J., Ludowyke, R.I., 1999. Increases in phosphorylation of the myosin II heavy chain, but not regulatory light chains, correlate with insulin secretion in rat pancreatic islets and RINm5F cells. Diabetes 48, 2383-2389.

Yaney, G.C., Fairbanks, J.M., Deeney, J.T., Korchak, H.M., Tornheim, K., Corkey, B.E., 2002. Potentiation of insulin secretion by phorbol esters is mediated by PKC-a and $\mathrm{nPKC}$ isoforms. Am. J. Physiol. Endocrinol. Metab. 283, 880-888.

Zhu, A.X., Zhao, Y., Moller, D.E., Flier, J.S., 1994. Cloning and characterization of p97 MAPK, a novel human homolog of rat ERK3. Mol. Cell. Biol. 12, 8202-8211. 